\title{
PERILAKU BALOK BAJA I NON PRISMASTIS (TAPERED BEAM)
}

\author{
Titin Sundar ${ }^{1}$, Agoes Soehardjono ${ }^{2}$ dan Wisnumurti ${ }^{2}$ \\ 1 Mahasiswa / Program Pasca Sarjana / Jurusan Teknik Sipil / Fakultas Teknik / \\ Universitas Brawijaya \\ 2 Dosen / Jurusan Teknik Sipil / Universitas Brawijaya Malang \\ Korespondensi: tari1273@yahoo.co.id
}

\begin{abstract}
The use of bending structure components becomes economical if the cross section of the beam follows the moment-diagram form. In this research is a simple beam with concentrated load in the middle of the span, so that the height of the beam is maximum in the middle of span, too. The research purpose is to obtain the bending capacity and to know the buckling behavior for optimum design. The results are compared with theoretical calculations, and ANSYS validation. Concluded of this research that the larger the tapered constant, the greater the bending capacity. The smaller the tapered angle the greater bending capacity. For the same tapered angle with higher $h_{\max }$, the bending capacity is also greater. The collapse occurring on this beam is the lateral torsional buckling.
\end{abstract}

Keywords: tapered constant, angle tapered, moment capacity, lateral torsional

\section{PENDAHULUAN}

Balok non prismastis adalah balok yang mempunyai penampang tidak sama di sepanjang bentangnya, Penggunaan komponen struktur lentur menjadi ekonomis jika penampang balok mengikuti bentuk bidang momennya. Contohnya, simple beam dengan beban terpusat di tengah bentang diagram momennya bilinear [1], oleh karena itu ukuran tinggi balok dibuat bentuk tapered sesuai bidang momen. Dasar pemikiran sistem tapered ini sederhana bahwa ukuruan (tinggi) balok disesuaikan dengan besarnya momen yang terjadi [2]. Tapered (varying depth) adalah salah satu teknik baru dalam desain agar ekonomis dan mengurangi berat sendirinya [3].

Dalam penelitian ini balok baja tapered dibuat dengan memotong lembaran pelat baja menjadi elemen-elemen pelat untuk sayap dan badan dengan menggunakan pengelasan sehingga membentuk suatu profil I dengan sayap prismastis dan badan non prismatis (badan tapered). Konstruksi balok baja ini bertumpuan sederhana dengan dibebani beban perpusat $P$ ditengah bentang.
Tujuan yang diharapkan dari penelitian ini adalah sebagai menganalisis kapasitas lentur balok baja profil I non prismatis (tapered I beam) dari berbagai bentuk geometri yang berbeda dengan volume yang sama sehingga diketahui kapasitas yang maksimum, dan mendapatkan perilaku tekuk akibat lentur yang terjadi pada berbagai bentuk model tersebut.

\section{KAJIAN PUSTAKA}

Seperti kita ketahui bahwa balok merupakan kombinasi dari elemen struktur tekan dan elemen struktur tarik. Bagian sayap tekan balok dihubungkan dengan bagian sayap tarik melalui badan balok sehingga dapat mencegah terjadinya ketidakstabilan sayap tekan terhadap tekuk. Komponen tekan dari suatu balok disokong seluruhnya oleh komponen tarik yang stabil. Jadi tekuk global dari komponen tekan tidak akan terjadi sebelum kapasitas momen batas penampang belum tercapai. Namun jika momen $M$ ditambahkan terus sampai momen kritis $M_{c r}$ maka saat itulah terjadi tekuk kearah lateral yang disebut sebagai lateral torsional buckling 
(LTB), yaitu balok mengalami deformasi arah lateral dan berotasi cukup besar secara tiba-tiba sehingga struktur tidak stabil dan terjadilah keruntuhan total.

Besarnya kapasitas lentur/kuat nominal momen lentur dari penampang ditentukan sebagai berikut:

Kasus 1, agar penampang dapat mencapai kuat nominal $M_{n}=M_{p}$, maka penampang harus kompak untuk mencegah terjadinya tekuk lokal. Syarat penampang kompak ditentukan sesuai SNI 03-1729-2002 [4], yaitu $\lambda$ untuk flens $\left(b / 2 t_{f}\right)$ dan untuk web $\left(h / t_{w}\right)$ tidak boleh melebihi $\lambda_{p}$. Selain harus kompak, pengaku lateral harus dipasang sehingga panjang bentang tak terkekang $L$ tidak melebihi $L_{p d}$ ( $L \leq L_{p d}$ ).

$L_{p d}=\frac{25000+15000\left(\frac{M 1}{M p}\right)}{f y} x r_{y}$

Kasus 2, agar penampanng dapat mencapai momen plastis $M_{p}$, dengan kapasitas rotasi $\mathrm{R}<3$, maka penampang harus kompak dan tidak terjadi tekuk lokal. Pengaku lateral dipasang sehingga $L<L_{p}$

$L_{p}=\frac{790}{\sqrt{f_{y}}} r_{y} \quad($ untuk $\mathrm{E}=200000 \mathrm{MPa})$

Kasus 3, dalam kasus ini terjadi tekuk torsi lateral untuk penampang $\operatorname{kompak}\left(\lambda<\lambda_{p}\right)$. Kuat nominal didekati dengan hubungan linear antara titik $1\left(L_{p}, M_{p}\right)$ dengan titik $2\left(L_{r}, M_{r}\right)$ pada Gambar 2. Kuat momen lentur nominal ditentukan :

$M_{n}=C_{b}\left(M_{r}+\left(M_{p}-M_{r}\right)\left(\frac{L_{r}-L}{L_{r}-L_{p}}\right)\right) \leq M_{p}$

Kasus 4, terjadi jika:

$L_{p}<L<L_{r} ;$

$\lambda_{p}<\left(\lambda=b / 2 t_{f}\right)<\lambda_{r}$ (flens tak kompak);

$\lambda_{p}<\left(\lambda=h / t_{w}\right)<\lambda_{r}$ (web tak kompak), maka

kuat momen lentur nominal dihitung berdasarkan keadaan yang paling kritis dari tekuk lokal flens, tekuk lokal web, atau tekuk torsi lateral. Untuk membatasi terhadap tekuk lokal flens serta tekuk lokal web, SNI 07-1729-2002 [4] merumuskan:

$M_{n}=M_{p}-\left(M_{p}-M_{r}\right) \frac{\lambda-\lambda_{p}}{\lambda_{r}-\lambda_{p}}$

Sedangkan kondisi batas untuk tekuk torsi lateral ditentukan berdasarkan:

$M_{n}=C_{b}\left(M_{r}+\left(M_{p}-M_{r}\right)\left(\frac{L_{r}-L}{L_{r}-L_{p}}\right)\right) \leq M_{p}$
Kasus 5, terjadi bila $L>L_{r}$, dan kelangsingan dari flens dan web tidak melebihi $\lambda_{r}$ (penampang kompak). Kuat nominal momen lentur dalam kondisi ini ditentukan:

$M n=M_{c r}=C_{b} \frac{\pi}{L} \sqrt{E I_{y} G J+\left(\frac{\pi E}{L}\right)^{2} I_{y} C_{w}}$

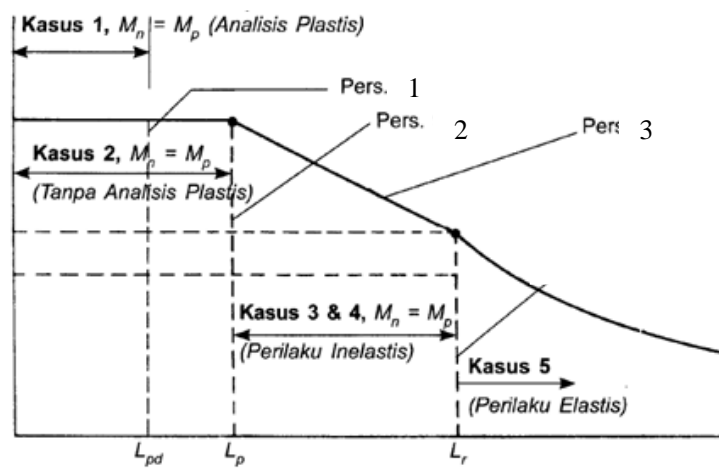

Gambar 1. Kuat momen nominal akibat tekuk torsi lateral

Sumber: Setiawan A [5]

Berdasarkan penelitian Raftoyiannis, IG dan Adamakos T[6] mempelajari stabilitas tapered I beam terhadap beban lentur dengan penentuan beban tekuk kritis LTB dari badan tapered I beams dengan karakteristik geometrik seperti Gambar 2.

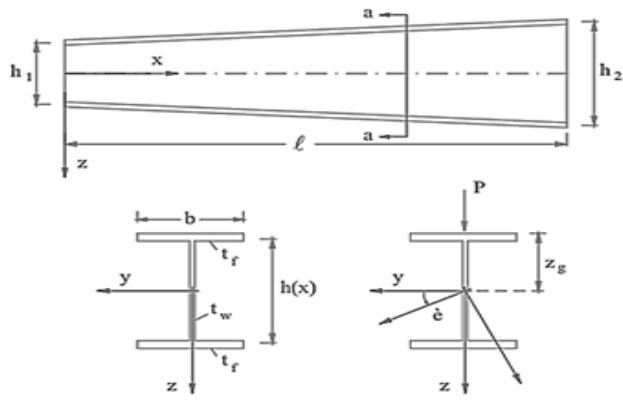

Gambar 2. Karakteristik geometrik dari tapered I- beam

Sumber: Raftoyiannis, IG [6]

Hasil penelitiannya seperti pada Gambar 3 bahwa rasio beban kritis $P_{c r} / P_{c r}$ versus rasio tapered $h_{2} / h_{1}$ dengan berbagai variasi panjang yang terbuat dari profil IPE-300. Beban terdiri dari beban terpusat $\mathrm{P}$ yang diaplikasikan di tengah bentang pada top flange dengan $z_{g}=h_{0} / 2$. Terlihat jelas bahwa rasio tapered meningkat dari $h_{2} / h_{1}=1$ (uniform beam) ke $h_{2} / h_{1}=3$ (tapered beam), beban kritis $P_{c r}$ menurun dan bahkan lebih jelas pada kasus balok dengan bentang pendek. 


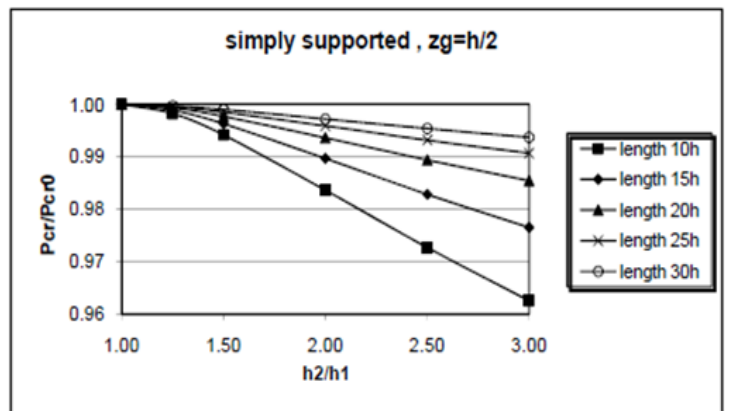

Gambar 3. Rasio beban kritis $P_{c r} / P_{c r 0}$ versus rasio taper $h 2 / h 1$ untuk variasi rasio kelangsingan dari simple supported beam dengan beban terpusat $\mathrm{P}$ diaplikasikan di sayap

Sumber: Raftoyiannis, IG [6]

Berdasarkan penelitian Yeong-Bin Yang, A. M. ASCE, dan Jong Dar Yau [7], bahwa beban kritis tapered I beam untuk simple beam dengan beban terpusat di sayap atas, lebar sayap dan tinggi web bervarisi linier dari tengah ke tepi. Hasil kedua kasus ini seperti ditunjukkan Gambar 4. Seperti ditunjukkan pada Gambar 4, bahwa solusi Yeong sesuai dengan Kitipornchai and Trahair (1972), yaitu untuk taper constant mulai 0,1 sampai 0,4 beban kritis turun untuk depth tapered kemudian untuk taper constant lebih besar dari 0,4 beban kritis naik lagi. Taper constan dalam hal ini adalah nilai $h$ minimum dibanding dengan $h$ maksimum di tengah bentang.

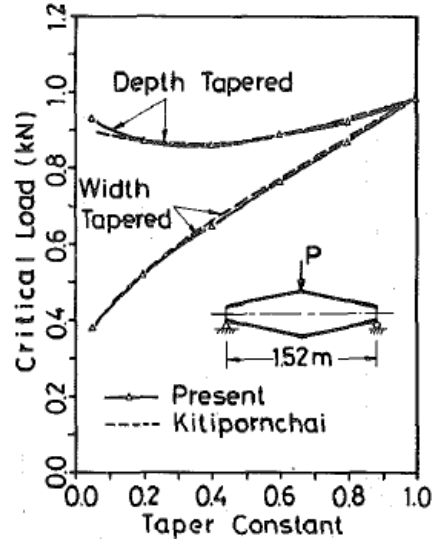

Gambar 4. Beban kritis tapered beam dengan beban di sayap atas Sumber: Yang, YB [7]

Yeong juga meneliti pengaruh variasi posisi pembebanan pada balok tapered. Pengaruh / efek dari posisi beban terpusat pada balok tapered, yaitu bahwa beban kritis semakin kecil secara berurutan jika posisi beban dilakukan di bottom flange, centroid, dan top flange dengan trend line yang sama seperti terlihat pada Gambar 5.

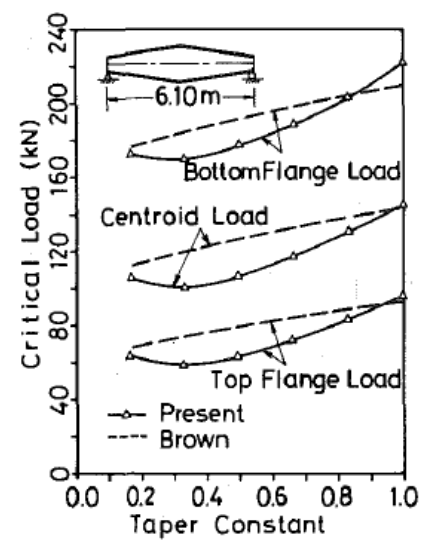

Gambar 5. Beban kritis tapered beam dengan variasi posisi beban Sumber: Yang, YB [7]

\section{METODE PENELITIAN}

\subsection{Diagram Alir Penelitian}

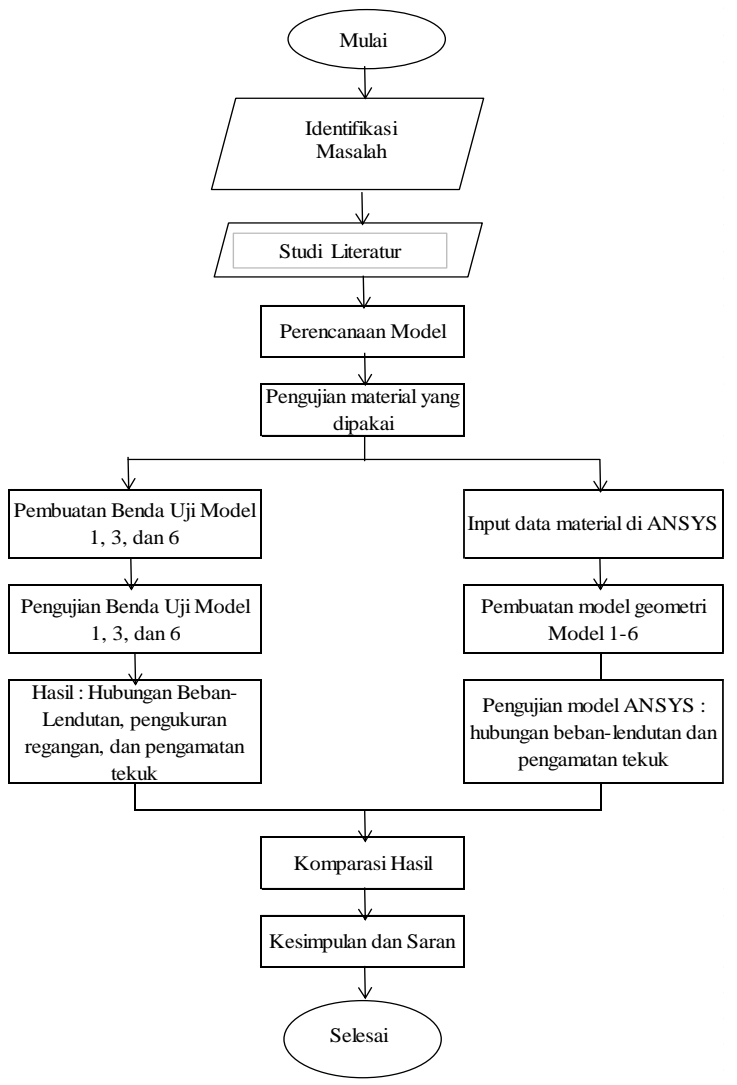

Gambar 6. Diagram alir penelitian.

\subsection{Rancangan Penelitian}

Ada 6 model benda uji dengan ukuran seperti ditunjukkan Tabel 1 dan model variasi tapered ditunjukkan Gambar 7. Pengujian eksperimen yang dilakukan adalah model 1, 3, 
dan 6 dengan jumlah benda uji 2 buah untuk masing-masing model.

Tabel 1. Ukuran model benda uji

\begin{tabular}{|c|c|c|c|c|c|c|}
\hline Model & $\begin{array}{c}\text { Sudut } \\
\text { tapered } \\
(ø) \\
0\end{array}$ & $\begin{array}{c}\text { Tinggi web } \\
\text { tengah } \\
\left(h_{\max }\right) \\
m m \\
\end{array}$ & $\begin{array}{c}\text { Volume } \\
\text { model } \\
\\
m m 3\end{array}$ & \multicolumn{2}{|l|}{ Ukuran penampang } & Sketsa penampang \\
\hline 1 & 90 & 90 & 576000 & Tebal flens (tf) : & $3 \mathrm{~mm}$ & $b f \quad-$ \\
\hline 2 & 7.60 & 100 & 576796 & Lebar flens (bf): & $50 \mathrm{~mm}$ & \\
\hline 3 & 6.42 & 105 & 576757 & Tebal web (tw) : & $2 \mathrm{~mm}$ & \\
\hline 4 & 5.71 & 110 & 576148 & Tinggi web tepi $\left(\mathrm{h}_{\min }\right)$ : & $60 \mathrm{~mm}$ & hw \\
\hline 5 & 5.71 & 115 & 576823 & Panjang balok $(\mathrm{L})$ : & $135 \mathrm{~mm}$ & \\
\hline 6 & 5.71 & 120 & 576898 & & & \\
\hline
\end{tabular}

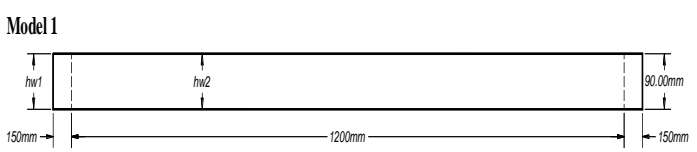

Model2

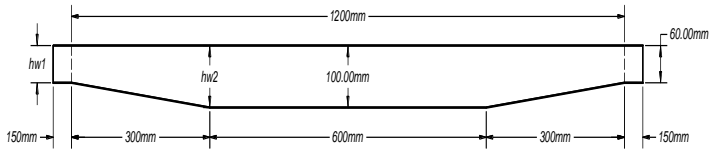

Model 3

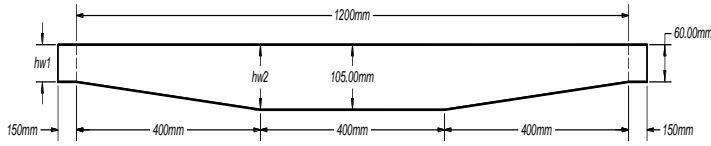

Model 4

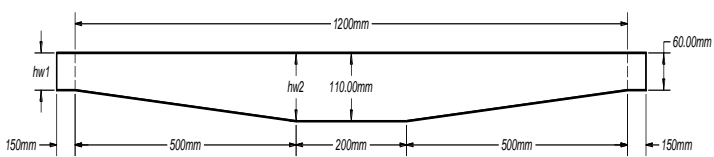

Model5

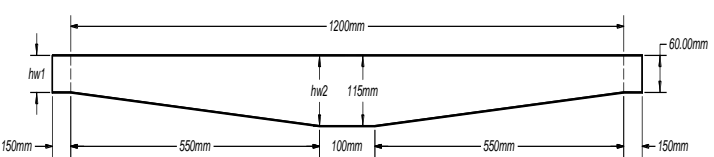

Model 6

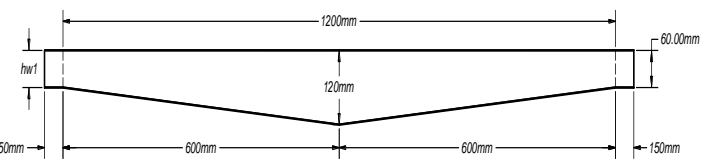

Gambar 7. Model dan ukuran benda uji

\subsection{Pengujian Eksperimen}

Untuk uji tarik material, model uji sesuai SNI 07-0371-1998[8] digunakan UTM (Universal Testing Machine) dan untuk uji specimen Model digunakan Loading frame dan hydraulic jack dengan setting up seperti berikut:

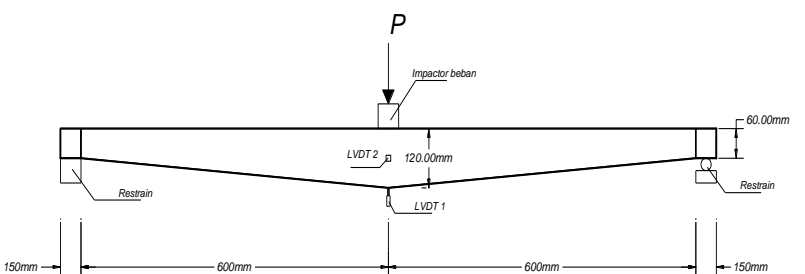

Gambar 8. Ilustrasi setting up pengujian

\section{HASIL DAN PEMBAHASAN}

\subsection{Hasil Uji Tarik}

Dari hasil pengujian ini didapatkan bentuk putus pelat baja seperti Gambar 9 dan kurva hubungan tegangan-regangan seperti Gambar 10, dengan rekapitulasi hasil uji ditunjukkan pada Tabel 2.

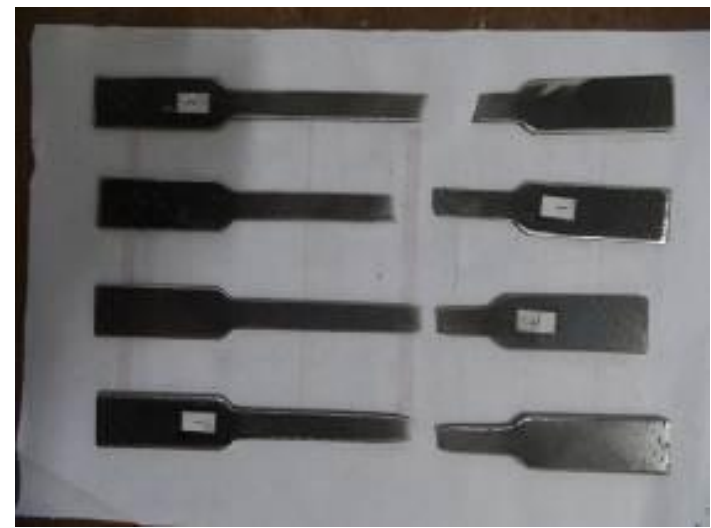

Gambar 9. Bentuk putus uji tarik pelat baja

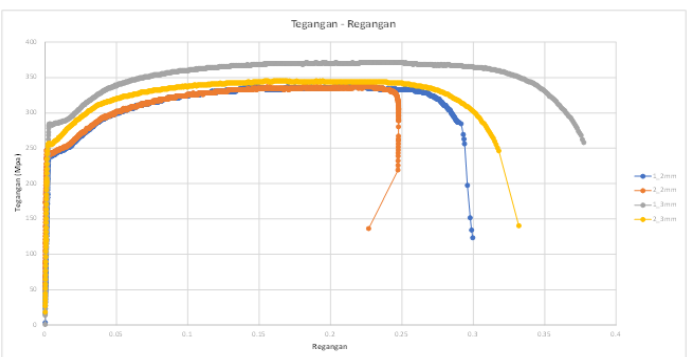

Gambar 10. Kurva hubungan Tegangan-regangan

Tabel 2. Rekapitulasi Hasil Uji Tarik Pelat

\begin{tabular}{cccc}
\hline Nama Benda Uji & Tegangan leleh (Mpa) & Tegangan ultimat (Mpa) & Modulus elastisitas (Mpa) \\
\hline No 1 Tebal 2mm & 236.68 & 336.96 & 116209 \\
No 2 Tebal 2mm & 236.68 & 336.96 & 757478 \\
No 1 Tebal 3mm & 281.307 & 371.38 & 124988 \\
No 2 Tebal 3mm & 252.24 & 345.23 & 194406 \\
\hline
\end{tabular}

4.2 Hasil Pengujian

\subsubsection{Pembahasan analitis/teoritis}

Perhitungan momen kapasitas penampang sesuai dengan syarat-syarat yang ada di SNI 03-1729-2002[4] untuk balok 
prismastis (sudut tapered mendekati $90^{\circ}$ ) dan untuk balok non prismastis (tapered) dengan menggunakan tinggi penampang di tengah bentang $\left(h_{\max }\right)$. Berdasarkan perhitungan analitis ini, dari Model 1 sampai dengan Model 6 termasuk kasus 3 yaitu terjadi tekuk torsi lateral untuk penampang kompak $\left(\lambda<\lambda_{p}\right)$ dengan kuat momen lentur nominal sesuai persamaan (3). Hasil hitungan disajikan pada Tabel 3, tekuk torsi lateral terjadi karena $L$ < $L_{p}$.

Tabel 3. Momen kapasitas penampang

\begin{tabular}{cccc}
\hline Model & $\begin{array}{c}\text { Sudut } \\
\emptyset^{\circ}\end{array}$ & $\begin{array}{c}\text { Tapered constant } \\
(\mathrm{A} / \mathrm{V})\end{array}$ & $\begin{array}{c}\text { Mn } \\
(\mathrm{kNm})\end{array}$ \\
\hline 1 & $\approx 90$ & 0.83 & 4.22 \\
2 & 7.60 & 0.87 & 4.80 \\
3 & 6.42 & 0.88 & 5.02 \\
4 & 5.71 & 0.90 & 5.24 \\
5 & 5.71 & 0.92 & 5.47 \\
6 & 5.71 & 0.94 & 5.69 \\
\hline
\end{tabular}

Seperti terlihat pada Tabel 3, bahwa makin kecil sudut tapered maka makin besar momen kapasitasnya. Untuk Model 4, 5, dan 6 dengan sudut tapered yang sama kapasitasnya semakin juga semakin besar hal ini karena $h_{\max }$ model 4,5 , dan 6 juga makin besar, sehingga dalam hal ini Model 6 dengan bentuk badan tapered sesuai diagram bidang momen yang mempunyai kapasitas maksimum. Sudut tapered adalah sudut yang dibentuk oleh selisih $h_{\max }$ dan $h_{\min }$ dibanding panjang horisontalnya, misal untuk Model 6, sudut $\varnothing=\operatorname{arc}$ tan $(120-60) / 600=5.71^{\circ} . \quad$ Tapered constant disini adalah perbandingan luas penampang ditengah bentang dibanding dengan volume total (dalam hal ini volume benda uji adalah tetap/konstan). Jadi makin tinggi $h_{\max }$ di tengah bentang makin besar luas penampangnya dan makin besar pula tapered constantnya, makin besar tapered constant semakin besar kapasitasnya.

\subsubsection{Pembahasan eksperimen}

Adapun Setting up pengujian dilakukan seperti pada Gambar 10. Strain gage dipasang pada sayap atas dan sayap bawah untuk mendapatkan nilai regangan. Perhitungan momen diambil pada saat nilai regangan sesaat sebelum leleh, yaitu pada saat awal mulai terjadi tekuk sebelum regangan mencapai regangan leleh $\left(\varepsilon_{\mathrm{y}}=0,0013\right)$. Nilai momen didapatkan dari gaya $C$ (compression) atau gaya $T$ (tension) dikalikan lengan momennya. Nilai gaya $C$ atau $T$ ini diperoleh dari nilai regangan dikalikan $E$ (modulus elastisitas) dikalikan luas penampangnya.

Hasil perhitungan momen disajikan pada tabel 4, bahwa momen semakin besar dari model 1, 3, dan 6. Untuk model 1 hasil eksperimen hampir sama dengan teoritis selisih $0.72 \%$ lebih rendah dari teoritis. Untuk model 3 hasil eksperimen $5.38 \%$ lebih tinggi dari teoritis, dan untuk model 6 , hasil eksperimen $7.21 \%$ lebih tinggi dari teoritis.

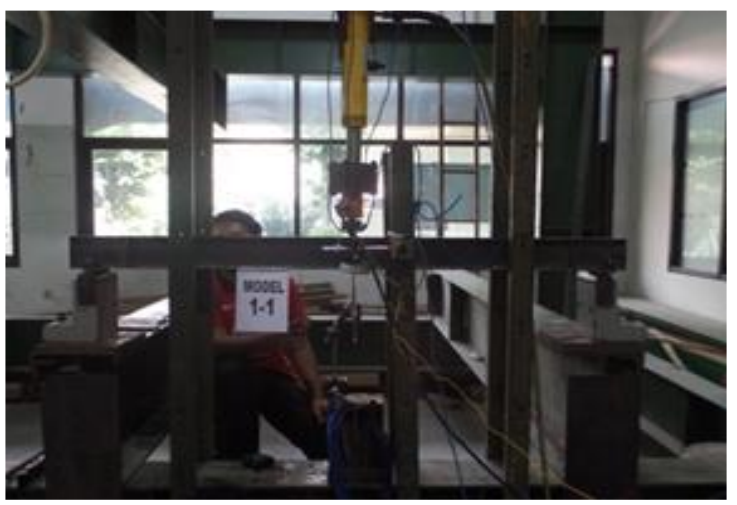

Gambar 11. Setting up pengujian

Dalam eksperimen ini kekakuaan sayap dan badan penampang dibuat kompak untuk mencegah terjadinya tekuk lokal pada sayap dan badan. Stiffner dipasang hanya pada tumpuan sehingga $L>L_{p}$ yang disyaratkan, dengan $L$ adalah panjang bentang tak terkekang. Jadi seperti yang terjadi pada analisa perhitungan teoritis, bahwa terjadi tekuk torsi lateral untuk penampang kompak. Terjadinya tekuk torsi lateral ditandai dengan mulai tidak seimbangnya (ketidakstabilan) regangan pada sayap atas sayap bawah.

Tabel 4. Momen sesaat sebelum leleh $\left(M_{n}\right)$

\begin{tabular}{cccccc}
\hline Model & Sudut & $\begin{array}{c}\text { Tapered } \\
\text { constant } \\
(\mathrm{A} / \mathrm{V})\end{array}$ & Benda uji 1 & Benda uji2 & Rata-rata \\
\hline 1 & $\approx 90^{\circ}$ & 0.83 & 4.06 & 4.32 & 4.19 \\
3 & 6.42 & 0.88 & 5.44 & 5.13 & 5.29 \\
6 & 5.71 & 0.94 & 6.39 & 5.81 & 6.10 \\
\hline
\end{tabular}

Tekuk torsi lateral yaitu suatu keruntuhan yang terjadi jika momen $M$ ditambahkan terus sampai momen kritis $M_{c r}$ maka saat itulah terjadi tekuk kearah lateral yang disebut sebagai lateral torsional buckling $(L T B)$, yaitu balok mengalami deformasi arah lateral dan berotasi cukup besar secara tiba-tiba sehingga struktur tidak stabil dan terjadilah keruntuhan total seperti pada Gambar 12. 


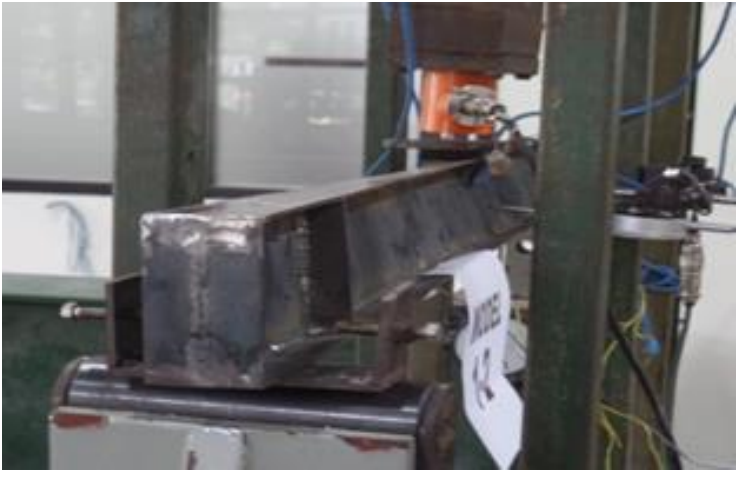

Gambar 12. Keruntuhan total pada benda uji

\subsubsection{Validasi dengan ANSYS}

Pada tahapan Engineering Data, didefinisikan material jenis Structural Steel Nonlinier dengan sistem multilinier isotropic, sehingga bisa dimasukkan nilai tegangan-regangan yang dihasilkan dari pengujian material. Tahap Geometry, didefinisikan geometri dari model benda uji yang sebelumnya dibuat $3 D$ dengan Autocad, kemudian hasilnya diimport ke ANSYS dengan format.iges. Tahap Model dan Set Up, difenisikan contact body antar elemen, jenis perletakan, dan load step yang akan diaplikasikan pada model benda uji sesuai dengan tahapan pemberian beban yang dilakukan pada saat pengujian eksperimen., agar perilakunya menyerupai simple beam. Dalam tahap ini juga didefinisikan ukuran dan bentuk mesh dari model benda uji. Tahap terakhir dalah solution and result.

Keruntuhan dari analis ANSYS ini seperti digambarkan pada Gambar 13 dan perhitungan momen ditabelkan pada Tabel $\mathbf{5}$. Perhitungan momen dihitung dari hubungan beban-lendutan pada saat $P$ mencapai kondisi in elastic, pada kondisi ini dilihat nilai tegangannya kemudian diperoleh nilai $M_{n}$.

Dari Tabel 5 juga menunjukkan momen $M_{n}$ semakin besar dari model 1 , 3, dan 6 dengan dengan nilai momen yang hampir sama dengan perhitungan teoritis SNI 03-1729-2002[4]. Untuk model 1, hasil eksperimen $3.46 \%$ lebih tinngi dari ANSYS, untuk model 3 hasil eksperimen $9.07 \%$ lebih tinggi dari ANSYS, dan untuk model 6 hasil eksperimen $7.02 \%$ lebih tinggi dari ANSYS. Hasil rekapitulasi dari ketiga pengujian ini ditunjukkan pada Tabel 6.
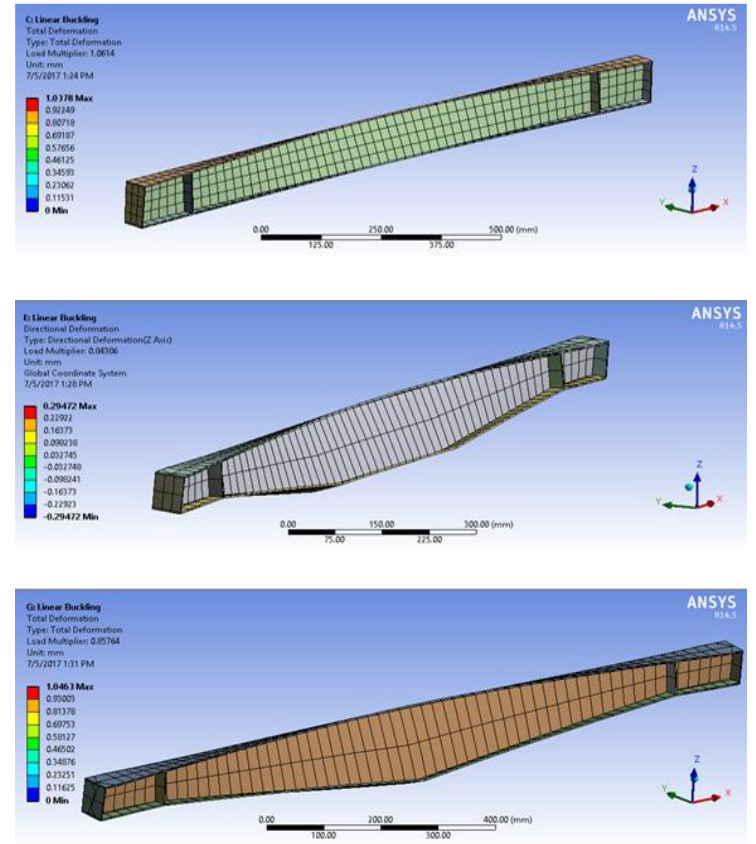

Gambar 13. Keruntuhan benda uji Model 1, 3, dan 6 berdasarkan analisa ANSYS

Tabel 5. Perhitungan momen berdasarkan

\begin{tabular}{cccc}
\multicolumn{4}{c}{ analisa $A N S Y S$} \\
Model & Sudut & Tapered constant & Mn \\
& $\emptyset^{0}$ & $(\mathrm{~A} / \mathrm{V})$ & $(\mathrm{kNm})$ \\
\hline 1 & $\approx 90$ & 0.83 & 4.05 \\
3 & 6.42 & 0.88 & 4.85 \\
6 & 5.71 & 0.94 & 5.70 \\
\hline
\end{tabular}

Tabel 6. Rekapitulasi hasil pengujian teoritis, eksperimen, dan ANSYS

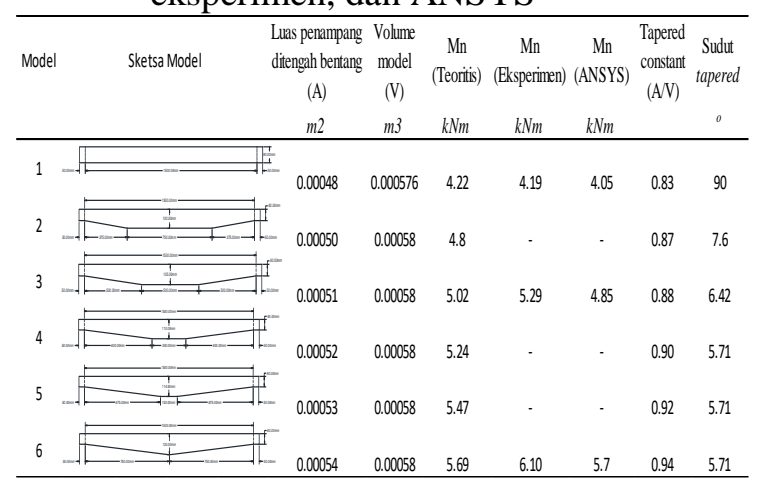

Bahwa berdasarkan pengujian teoritis, eksperimen, maupun ANSYS menunjukkan bahwa semakin besar tapered constant kapasitas momen lentur juga meningkat. 
Peningkatan kapasitas lentur dari model 1 sampai dengan model 6 ditunjukkan dengan diagram batang pada Gambar 14. Bahwa hasil pengujian teoritis, eksperimen, dan ANSYS mempunyai trend hampir sama dan hasil pengujian eksperimen lebih tinggi dibanding hasil teoritis dan ANSYS. Kurva hubungan tapered constant dengan momen kapasitas disajikan pada Gambar 15.

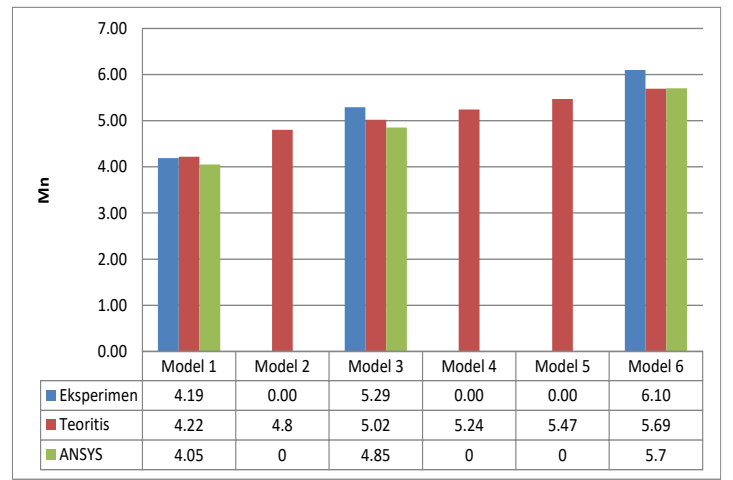

Gambar 14. Diagram batang kapasitas lentur dari berbagai model pada pengujian teoritis, eksperimen, dan ANSYS

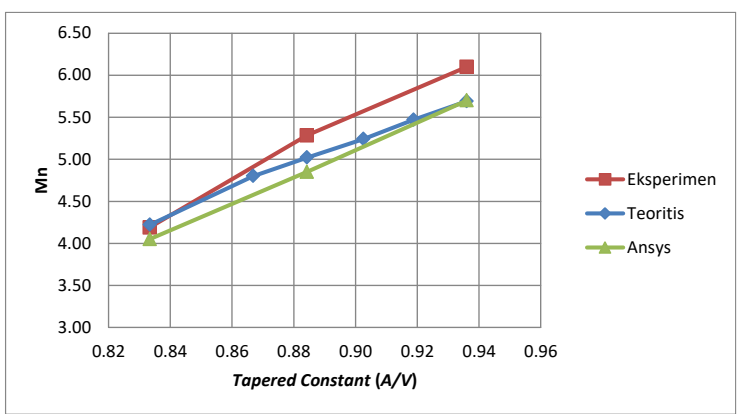

Gambar 15. Kurva hubungan tapered constant dan momen kapasitas $M_{n}$ untuk berbagai model pada pengujian teoritis, eksperimen, dan ANSYS.

\section{KESIMPULAN DAN SARAN \\ 6.1. Kesimpulan}

Berdasarkan hasil penelitian dengan perhitungan teoritis sesuai SNI 03-1729-2002 [4], pengujian eksperimen, maupun analisis numerik dengan ANSYS, dapat diambil beberapa kesimpulan seperti berikut:

1. Semakin besar luas penampang dengan volume yang sama (tapered constant) maka makin besar kapasitas lenturnya. Atau makin kecil sudut tapered kapasitas lenturnya makin besar (Model 1 sampai dengan Model 3), untuk Model 4 sampai dengan Model 6 mempunyai sudut tapered yang sama tetapi $h_{\max }$ makin tinggi (bentuk tapered semakin mendekati bentuk diagram momen) maka luas penampang juga makin besar sehingga kapasitas lenturnya juga semakin besar. Peningkatan kapasitas lentur dari balok prismastis ke balok tapered ini sekitar $31 \%$. Hasil yang diperoleh dari pengujian eksperimen lebih tinggi dibanding pengujian teoritis maupun ANSYS.

2. Jenis keruntuhan yang terjadi pada balok prismastis dan non prismastis (tapered) ini adalah keruntuhan tekuk torsi lateral.

\subsection{Saran}

Untuk penelitian selanjutnya dapat dilakukan pengujian balok tapered dengan adanya pengaruh kekangan lateral terhadap kapasitas lentur tapered beam.

\section{DAFTAR PUSTAKA}

[1] Chen, W.F. and Lui, E. M. Structural Stability Theory and Implementation. New York: Elsevier Science Publishing Co., Inc. 1987.

[2] Dewobroto, W. Struktur Baja Perilaku, Analisis, dan Desain-AISC 2010. Jakarta: Grand Melia. 2011

[3] Bhurke, K. N et al. Strength of Welded Plate Girder with Tapered Web. International Journal of Engineering Research and Applications. ISSN: 2248-9622, Vol. 3, Issue 5, pp. 1947-1951. 2013.

[4] Anonim. Standar Nasional Indonesia 03-1729-2002 Tata Cara Perencanaan Struktur Baja untuk Bangunan Gedung. Departemen Pekerjaan Umum. 2002.

[5] Setiawan, A. Perencanaan Struktur Baja dengan Metode LRFD (Berdasarkan SNI 03-1729-2002). Jakarta: Erlangga. 2008.

[6] Raftoyiannis, I. G and Adamakos, T. Critical Lateral Torsional Buckling Moments I-beams. The Open Construction and Building Technologi Journal, 2010, 4, 105-112.

[7] Yang, Y. B., ASCE, A. M., and Yau J. D. Stability of Beam with Tapered I-Sections. Journal of Engineering Mechanics, vol. 113, No. 9, OASCE, ISSN 0733-9399/87/0009-133 7/\$01.00. 1987. Paper No. 21798.

[8] Anonim. Standar Nasional Indonesia 07-0371-1998 Batang Uji Tarik untuk Bahan Logam. Badan Standar Nasional. 1998. 